\title{
An Analysis of Compliment Responses by Kuwaiti EFL Learners: A Pragmatic Approach
}

\author{
Abdullah M. Alotaibi \\ Associate Prof at PAAET \& CBE, Kuwait
}

doi: 10.19044/esj.2016.v12n10p74 URL:http://dx.doi.org/10.19044/esj.2016.v12n10p74

\begin{abstract}
This study investigates the extent to which 80 female Kuwaiti EFL learners produce target-like compliment responses when they are communicating in English, through comparing their responses to those of British English speakers. It also examines whether the English proficiency level of Kuwaiti EFL learners plays a role in their responses to compliments in English. Essentially, this study explores whether pragmatic transfer has an impact on the Kuwaiti participants' responses. A Discourse Completion Task (DCT) was given to 50 female native speakers of British English (the control group) and to 80 female Kuwaiti EFL learners (the treatment group), in order to determine whether the responses of the latter group are similar or different to those of the former group. The results reveal that the English proficiency level of the treatment group had no effect on their answers on the DCT. In comparison with the control group, the results also demonstrate that the treatment group transferred both L1 expressions and strategies to respond to compliments in English. This has been attributed to the fact that they may not be aware of any culture-specific nature of verbal communications crosslinguistically, among other reasons. Finally, the study concludes with recommendations for further research.
\end{abstract}

Keywords: Compliment responses, pragmatic transfer, cultural awareness, pragmatic competence, Kuwaiti EFL learners

\section{Introduction}

For decades, researchers believed that learning a second or foreign language means that one should attain linguistic or grammatical accuracy. However, a great shift in focus has occurred since the communicative approach has emerged, the primary attention has begun to shift to functional and communicative abilities in L2. In particular, this approach gives special attention to the comprehension and production of language which is suitable to communicate with others, conforming to specific sociocultural parameters 
(Thomas, 1983). The inability to do so may result in misunderstandings, and in some cases communication breakdowns. Verbal communication with speakers of other languages can be regarded as a challenge to many learners worldwide. This communicative behaviour requires two types of competence, linguistic and pragmatic. The former refers to the ability to use the language itself, including the phonology, grammar and lexis, whereas the latter refers to the ability to use the language in an appropriate manner in various social situations. However, one may argue that linguistic competence is a pre-requisite to pragmatics (Schmidt, 1993). Put differently, one may not be able to be pragmatically appropriate without having the necessary tools to express oneself. It can be argued that this ability which enables L2 learners to express themselves in a suitable manner in different situations is integral in L2 education. Mastering this ability would facilitate communication with the speakers of other languages, helping them to avoid any communication breakdowns. Therefore, this study aims to investigate the ability of 80 female Kuwaiti EFL learners to produce target-like compliment responses in English by comparing their responses to those of British English speakers. It also aims to test whether the English proficiency level of Kuwaiti EFL learners plays a role in their ability to produce these responses. The ultimate goal of this study is to determine whether pragmatic transfer influences Kuwaiti EFL learners' responses on the DCT.

\section{Literature review}

\section{Pragmatic competence}

Pragmatics is mainly concerned with studying language from the perspective of users; it gives special attention to the language choices they make, the problems they face in using language in various social situations, and the influence of their language choices on the other interlocutors (Crystal, 1970, p.103). Originally, this term was situated within the philosophy of language (Morris, 1938). However, it has developed from the philosophy of language to be associated with sociolinguistics. In recent years, this terms has been used in L2 acquisition and teaching, in particular, to refer to pragmatic competence. In this respect, pragmatic competence is used to refer to one of the abilities which is subsumed by the broader concept of communicative competence. One of the early definitions provided for pragmatic competence was proposed by Chomsky (1980, p. 224). Specifically, he defines this type of competence as the knowledge of the suitable use of language in compliance with different purposes. This concept stands in contrast to the concept of grammatical competence; the latter refers to the knowledge of form and meaning (Chomsky, ibid). Canale (1983) places pragmatic competence in a contextualised mould. Particularity, Canale proposes that this type of competence is an important constituent of 
communicative competence. It is recognised as sociolinguistic competence, which refers to the knowledge of contextually suitable language (Canale, 1983). In 1988, Canale published another paper and expanded the definition of pragmatic competence to integrate illocutionary competence, i.e. the knowledge of pragmatic rules which are used to perform appropriate language functions (p. 90). In this way, pragmatic competence includes sociolinguistic competence which is concerned with performing language functions in a suitable manner in a particular context, together with illocutionary competence. Taking Canale's (1983) definition into account, in another recent study, Rose (1999) suggests another definition of pragmatic competence. In Rose's view, pragmatic competence is the ability to utilise language resources (i.e. pragmalinguistics) in a contextually suitable manner (i.e. sociopragmatics). This definition has been accepted and used by many linguists such as Leech (1983).

Mastering this type of competence could be viewed as a stumbling block for L2 learners. This can be accounted for by the fact that L2 learners are required to obtain the ability to use the language for various purposes, go beyond the language and comprehend the speaker's intended message, and understand the rules through which utterances combine to create a meaningful discourse (Bialystok, 1993). One may suggest that this could be potentially problematic to L2 learners. Rizk (2003) argues that what is considered suitable in a certain language may not be so in another language. For instance, describing someone as old in Chinese is positive, since it denotes someone who is wise and respected. However, doing so in the USA may be considered rude (Liu and Zhong, 1999). Many problems facing L2 learners are mainly pragmatic. Usually, L2 learners transfer the knowledge and norms associated with L1 into L2 context, resulting in producing potentially bizarre or inappropriate expressions. This type of transfer is explained in the following subsection.

\section{Pragmatic transfer}

In general, the term "transfer" refers to the influence of an established knowledge on the acquisition process of a new knowledge. According to Sternberg (1995, p. 342-5), a new situation is often approached with an existing mental set that is, a state of mind that involves an existing disposition to contemplate a situation in a certain way. Interestingly, these mental sets are mainly governed by culture-specific aspects. Hence, interactions between people who belong to different cultural backgrounds may be affected by the difference in their mental sets. Lack of awareness of the differences between mental sets may result in misunderstandings and communication breakdowns. This occurs because the interlocutors carry over their L1 knowledge from a situation of intracultural interaction and transfer it 
to another situation of intercultural interaction. In psychological terms, transfer is defined as the carryover of information or skills from one situation to another. Similarly, pragmatic transfer refers to the carryover of pragmatic knowledge from one language to another in a given context (Huth, 2006, p. 2045).

Until now, there is no clear procedure for determining whether a communicative act is affected by pragmatic transfer. Nevertheless, assuming that this type of transfer may have had an impact on a certain communicative act can be supported by observations which concentrate on the communicative behaviour of learners in both their L1 and L2. Then, these behaviours are compared to the linguistic behaviour of native speakers of L2 or the target language. An example of such situations is responses to compliments. Holmes (1988, p. 446) defines a compliment as "a speech act which explicitly attributes credit to someone other than the speaker, usually the person addressed, for some 'good' possession, characteristic, skill, etc. which is positively valued by the speaker and the hearer". Cultures exhibit various strategies to respond to compliments. For instance, based on my observation as a native speaker of Arabic, in Arab societies in general, individuals usually tend to exaggerate when they respond to compliments. In other words, they do not respond with a simple 'thank you'. For instance, when conversing with a native speaker of English, an Arab respondent may respond to the following compliment: "thanks for this delicious dinner" as bilGaafyeh ya Somri 'I hope the food will make you healthy honey'. If such a reply is addressed to a native speaker of English, he/she may think that the response is bizarre. Here, it can be suggested that the Arab respondent has carried over L1 cultural knowledge that a prayer of good health is a suitable response to a compliment, whereas a simple response of acceptance is much more reasonable. This is what we call negative pragmatic transfer since the L2 learner has generalised from her pragmatic knowledge of L1 to L2 situation. This type of transfer may cause L2 learners embarrassment when communicating with speakers of other languages since they may produce inappropriate responses. This problem intensifies if teachers of English as a second/foreign language opt for not focusing on pragmatic knowledge inside the classroom (Eslami-Rasekh et al., 2004). Several researchers have emphasised the importance of acquiring pragmatic competence in L2 setting, paying attention to the use of language in an effective manner in order to comprehend language in context (El Samaty, 2005, p. 341). The next subsection reviews some studies on compliment responses.

\section{Studies on compliment responses}

According to Manes and Wolfson (1981, p. 130), the basic function of compliments is to establish and reinforce solidarity via expressing 
approval or appreciation. However, this aspect is not always identified by L2 learners (Hatch, 1992). In fact, many L2 learners prefer to use compliment formulas since they are easily recognised as compliments by speakers of the target language. The behaviour of responding to compliments is viewed as an intriguing type of speech acts since the communicative situation may pose the following challenge to the hearer: if the hearer accepts the compliment, then he/she may be perceived as immodest. On the other hand, if the hearer rejects the compliment, he/she may be regarded in a negative way, not showing appreciation for the speaker's opinion (Pomerantz, 1978). The crux of the problem in such a situation is that neither lack of humility nor lack of appreciation for the speaker is desirable. This explains why in various societies, there are different communicative strategies in a certain type of situation. The purpose of these strategies is mainly to avoid the above problem. Herbert (1986) revised Pomerantz work and proposed a schema of compliment responses based on the analysis of compliment responses by American English speakers:

Table 1. Herbert's (1986, p. 79) schema of compliment response strategies

\begin{tabular}{cc}
\hline Strategy & Example \\
\hline A. Agreement & \\
I. Acceptances & Thanks; thank you; [smile] \\
1. Appreciation Token & Thanks, it's my favourite too \\
2.Comment Acceptance & Really brings out the blue in my eyes, doesn't it? \\
3.Praise Upgrade & I bought it for the trip to Arizona. \\
\hline II. Comment History & My brother gave it to me. \\
\hline III. Transfers & So's yours. \\
1. Reassignment & \\
2. Return & It's really quite old. \\
\hline B. Non-agreement & Do you really think so? \\
\hline I. Scale down & I hate it. \\
\hline II. Question & \\
\hline III. Non-acceptances & \\
1. Disagreement & \\
2. Qualification & It's all right, but Len's is nicer \\
\hline VI. No Acknowledgment & \\
\hline C. Other Interpretations & \\
\hline I. Request &
\end{tabular}

It follows that if these strategies utilised for responding to compliments differ cross-culturally, such a divergence is expected to possibly yield pragmatic transfer. One of the researchers who investigated this issue is Yoon (1991). Specifically, he compared the compliment responses of speakers of monolingual American English and Korean with those of bilingual Korean-English speakers. The sample of the study included thirty-five native speakers of American English, forty speakers of Korean, and thirty three bilingual speakers of English and Korean. The 
participants were asked to complete a DCT in the form: write down what you would respond in the following communicative situations. The results revealed that there were statistically significant differences between the responses of American native speakers of English and Korean speakers. In particular, with respect to American English speakers, the results showed that they preferred to agree with the compliment provided by the speaker, whereas Korean speakers exhibited a preference for being modest. Comparing these results with those of Korean-English bilingual speakers, it was found that, similar to American English speakers, they showed preference for agreeing with the speaker but to a lesser extent. However, this tendency was higher than that of Korean speakers. These results may warrant two remarks: (1) pragmatic transfer, from Korean, played a significant role in the participants' answers on the DCT; and (2) with regard to EnglishKorean bilingual speakers, the pragmatic transfer was from American English to Korean. These results may indicate that carrying over pragmatic knowledge from one language to another is indeed a significant problem facing L2 learners.

In a related vein, Chiang and Pochtraeger (1993) conducted a study to compare and contrast compliment responses provided by American English speakers and Chinese speakers. The results of the study demonstrated that American English speakers exhibited a higher degree of positive elaboration on compliments, whereas the Chinese speakers showed a higher degree of negative elaboration on compliments. A number of the latter group even denied the compliment. The two researchers indicated that American English speakers' preference of compliment responses excluded, to a great extent, negative responses such as rejection or denial. Conversely, as far as Chinese speakers are concerned, the results showed that this group usually thought that Americans have the tendency to pay compliments too freely. Hence, many of them believed that such responses may not be sincere. In fact, in a study conducted on compliment responses by Chinese speakers, Chang (1988) found that Chinese participants had a tendency to reject compliments, especially those given by a complimenter of higher status. These participants downgraded themselves by giving the credit to another individual rather than themselves. Once again, one may see that cultural differences contribute to the participants' views on compliment responses and the way they perceive the behaviour of the other.

Yoko (2003) carried out a study to investigate compliment responses by American English speakers and Japanese speakers. In particular, Yoko compared compliment responses provided by Japanese speakers with those given by American English speakers. The results revealed that Japanese speakers tended to reject compliments; they thought it is the accepted conduct in Japan, and that accepting compliments is undesirable. With regard 
to American English speakers, Yoko notes that the standard response to a compliment is a simple "thank you". This strategy has the advantage of accepting the compliment without necessarily showing an agreement with it, and avoiding being perceived as vain. According to Yoko (2003), compliments cause a conflict as far as the hearer is concerned, that is, the hearer need not reject the compliment, but he/she needs to show solidarity. Contrarily, in Japan, it is commonly accepted that individuals should not show an acceptance of compliments that are paid directly to them.

On the basis of the previous discussion, it seems that the behaviour of responding to compliments is significant in cross-cultural communication. The role played by pragmatic transfer in these communicative situations requires further investigation, since it may help L2 learners avoid embarrassing situations and improve their verbal communication skills in L2 setting. These issues have been tackled in various languages such as English, Korean, Chinese, etc. However, little attention has been given to compliment responses in Kuwaiti Arabic. Therefore, this study aims at bridging this gap by providing answers to the following questions:

1. What type of compliment response strategy do female Kuwaiti EFL learners and female British English speakers use?

2. To what extent are the compliment responses provided by female Kuwaiti EFL learners similar to those provided by female British English speakers?

3. Does the English proficiency level of Kuwaiti EFL learners play a role in responding to compliments in English?

The next section provides an overview of the methodology.

\section{Methodology}

Sample

80 female Kuwaiti EFL learners (the treatment group), speakers of Kuwaiti Spoken Arabic (KSA), and 50 female speakers of British English (the control group) participated in this study. The reason why I opted for only female participants is that; according to various studies (e.g. Holmes, 1988, 1998; Tannen, 1993; Guodong \& Jing, 2005), men and women differ in the way they perceive compliments. The former doubt the effectiveness of compliments as positive politeness means, whereas the latter conceive of compliments as ways of creating and reinforcing social bonds. Therefore, it is commonly accepted that women utilise compliments more than men (Guodong \& Jing, 2005). Due to the fact that the participants' English proficiency level was an independent variable, the female Kuwaiti EFL learners, mean age 23 years old, were divided into two groups on the basis of their results on the English Placement Test as follows: those who obtained scores ranging between 50-69 were considered intermediate (henceforth 
ILs), whereas those who scored 70-85 were considered advanced (henceforth ALs). The eighty participants were divided equally into: 40 ILs and 40 ALs. With regard to the control group, the 50 participants whose L1 is English were living in England at the time of the study; their ages ranged between 20-55. In order to validate the results, the participants were selected randomly. Specifically, the 80 female Kuwaiti participants were chosen from a 10000 population. The English speakers were also selected randomly from the streets of Newcastle upon Tyne (England), so that any individual would have had the opportunity to take part in the study. The next section provides a description of the data elicitation tool.

\section{Data elicitation tool}

The current study utilised one of the most commonly used elicitation tools in social pragmatics, namely, a Discourse Completion Task (DCT). This task is a written questionnaire that describes social situations, specifying the setting in which the communicative situation takes place, and in other cases factors such as social distance, solidarity, etc. (Blum-Kulka et at., 1989). This tool has been used by several researchers to investigate various speech acts cross-linguistically (e.g. Blum-Kulka, 1982; Yoon, 1991). In this study, the participants were asked to read the situations carefully and provide a response to the compliment specified in the short text provided. The DCT consisted of nine hypothetical scenarios in which a speaker pays a compliment and the participants were required to supply a response to that compliment (see Appendix 1).

\section{Statistical analysis}

In order to provide accurate findings, I utilised the Statistical Package for Social Sciences (SPSS). Specifically, calculations of the frequencies and means of the answers provided by Kuwaiti EFL learners and British English speakers were performed to determine whether there are any differences between the two groups. Additionally, a t-test was used to check whether the differences between ILs and ALs are statistically significant. Obtaining this result can help in determining whether the English proficiency level of the participants affected their answers on the DCT. The next section reports the results and discusses them.

\section{Results and discussion}

In this section, I present the answers provided by the participants on the DCT and discuss them. As previously mentioned, this study aims to explore the types of compliment response strategy utilised by Kuwaiti EFL learners (KELs) and British English speakers (BNSs). It also examines the extent to which 80 female Kuwaiti EFL learners produce target-like 
compliment responses when they are communicating in English. Finally, it tests whether English proficiency level of the KELs plays a role in their responses to compliments, paying special to whether their responses are influenced by their first language. Table 2 shows the results of the t-test.

Table 2. Results of t-test of differences between (ALs) and (ILs)

\begin{tabular}{ccccccc}
\hline Proficiency Level & $\mathrm{N}$ & $\mathrm{M}$ & $\mathrm{SD}$ & $\mathrm{t}$ & $\mathrm{df}$ & Sig. \\
\hline $\begin{array}{c}\text { Advanced Learners } \\
\text { (ALs) }\end{array}$ & 40 & 5.25 & 2.3 & 1.5 & 78 & $0.068^{*}$ \\
\hline $\begin{array}{c}\text { Intermediate Learners } \\
\text { (ILs) }\end{array}$ & 40 & 4.5 & 1.8 & & & \\
\hline & & $* P$ value $>0.05$ & &
\end{tabular}

The participants' results shown in Table 2 were based on whether their responses to the compliments in the DCT were influenced by their pragmatic knowledge of L1, rather than being correct or incorrect. Based on Table 2, it is clear that the English proficiency level of the participants had no impact on their answers on the DCT. The $P$ value $(0.068)$ is higher than (0.05), which means that the difference between ALs $(m=5.25)$ and ILS $(m=4.5)$ is not statistically significant. As far as strategy is concerned, Table 3 shows the percentages of KELs and BNSs in terms of compliment strategy.

Table 3. Percentage of KELs and BNSs in terms of compliment strategy

\begin{tabular}{ccc}
\hline Strategy & $\begin{array}{c}\text { Kuwaiti EFL learners } \\
\text { (KELs) }\end{array}$ & British English speakers (BNSs) \\
\hline Acceptance & & $50 \%$ \\
\hline Appreciation Token & $26 \%$ & $24 \%$ \\
\hline Comment Acceptance & $23 \%$ & $6 \%$ \\
\hline Praise upgrade & $5 \%$ & $16 \%$ \\
\hline Reassignment & & \\
\hline Return & $38 \%$ & $4 \%$ \\
\hline Non agreement & &
\end{tabular}

Table 3 shows that the BNSs provided appreciation tokens more frequently than the KELs (both ILs and ALs). In fact, half of BNSs (50\%) used appreciation tokens compared to $26 \%$ of the KELs. It is observed here that KELs avoid using appreciation tokens as often as BNSs do, and opt for a more eloquent response. This could be due to the fact that Arabs in general and Kuwaiti in particular believe that showing appreciation is not enough when responding to compliments; one needs to give a more wordy response that reflects a good image about him/her on the one hand, and pays sincere tribute to the complimenter on the other. Additionally, based on Table 3, similar to BNSs, KELs were found to provide acceptance responses to the compliments. That is, $23 \%$ and $24 \%$ of KELs and BNSs accepted the compliment on the DCT respectively. I noticed that the difference between the two groups in this category is that KELs provided more formulaic 
responses in comparison with BNSs. For instance, KELs provided the following responses in situation 2 on the DCT, in which a female friend compliments the speakers in her cooking:

1. bilhanah wiffifah 'I hope the food will give you joy and health'.

2. bilGaafyeh habiibti 'I hope the food will make you healthy love'.

Unlike BNSs, one may argue that KELs prefer such responses because such expressions are used in abundance in Kuwait. Knowing these expressions may give the impression that the person is generous and eloquent.

An examination of Table 3 demonstrates that KELs used the Return strategy more frequently than BNSs. For instance, 38\% of KELs used the Return strategy in which one returns the compliment paid to him/her by the speaker, whereas only $16 \%$ of BNSs used it. It is suggested that the significant difference between the responses on KELs and BNSs on this strategy could be ascribed to the fact that Kuwaitis are affected by their religion instructions (Islam), which ask them to be kind to the person to whom he/she is speaking, and to endeavour to be positive via ignoring the negative side of others and avoiding hurtful expressions (cf. Altakhaineh and Rahrouh, 2015). This tendency could be more frequent as far as KELs are concerned. Also, note that both KELs and BNSs responded to compliments while avoiding self-praise, i.e. only $5 \%$ and $6 \%$ of KELs and BNSs upgraded the praise respectively.

From another perspective, when compared with the responses provided by BNSs, the answers provided by KELs (both ILs and ALs) were not target-like since the participants carried over their pragmatic knowledge of L1 into their compliment responses in L2. In the remainder of this section, I present a number of the participants' responses on the DCT and analyse them to demonstrate how negative pragmatic transfer influenced the participants' responses. The responses provided by BNSs are the grounds on which I analyse the answers of KELs. The situations provided on the DCT will be supplied here for the reader's convenience.

Situation 1:

You have just finished presenting your research project in class, on your way back to your seat, one of your classmates says to you: "you were great, well done!". What would you say to her?

Most of the responses provided by BNSs on this situation were in agreement, e.g. "Oh! thanks!", "brilliant! Glad you liked it", etc. Two of the BNSs questioned the compliment by saying: "Really? I thought it was OK". On the other hand, many KELs responded by returning the compliment: "yours was better", or thinking that the complimenter wants her to help: "if you need any help with yours, let me know". It was observed that KELs 
transferred their pragmatic knowledge of L1 into their L2 responses, providing responses such as:

3. $\quad$ habiibti, killa min ooogit/k 'sweety, it is just because you are kind'.

4. tislamiin 'I hope you stay healthy'.

One may notice that KELs tend to use endearments, i.e. habiibti 'love' in their compliment responses. This tendency could be accounted for by the fact that Arabs in general and Kuwaitis in particular believe that one should be sweet-tongued to people as instructed by the prevalent traditions and Islamic teachings. This type of response may not be provided by a BNS. In fact, if such a response was addressed to a BNS, he/she may think it is bizarre. It appears that KELs have not only transferred the strategy they use in L1, but also the content of the compliment response to their English responses (see Yoon, 1991). KELs may have translated the above responses directly from L1, KSA. These answers present indisputable evidence that KELs pragmatically transferred their knowledge and compliment response strategy of L1 to L2 (cf. Huth, 2006). The same observation can be noted in the following situation from the DCT:

Situation 9:

Your father compliments you on your high grades at school, saying: "I'm proud of you. You are the role model to your siblings". What would you say to him?

On this item on the DCT, some of the KELs responses were:

5. Pana tSallamit minnik yubah 'I learned from you dad!'.

6. kill hattaSab Safaanitf yumma Pinti wu yubah, ?into mas?ooliyyti lamma tekburuun 'this success is for you mom, and you dad, I will take care of you when you grow old'.

It can be observed that the above responses reflect the Kuwaiti culture in which the individual considers him/herself a part of the family or tribe. In this way, the individual identifies him/herself by his/her family members. Expressing that one's success was done for one's parents, and promising to take care of one's parents when they grow old is a case of cultural transfer from KSA. Kuwaitis believe that they should repay their parents for their sacrifices by taking care of them when they grow old. In contrast, no such responses were supplied by BNSs. Probably, this is attributable to the difference of the culture between the Western and Eastern communities (cf. Altakhaineh and Zibin, 2014). Similarly, another common compliment response supplied by KELs on the DCT was to offer the complimented object to the complimenter (see situation 4 in the Appendix). Such a response was not offered by any of the BNSs.

Overall, the results may indicate that KELs believed that compliment responses follow universal rules regardless of the language. In other words, 
they may not be aware of any culture-specific nature of verbal communications cross-linguistically.

\section{Conclusion and recommendations}

This study explored the extent to which 80 female Kuwaiti EFL learners produce target-like compliment responses when they are communicating in English, through comparing their responses to those provided by British English speakers. Additionally, it examined whether the English proficiency level of the Kuwaiti participants plays a role in their responses to compliments. The results revealed the English proficiency level of the Kuwaiti participants had no impact on their responses on the DCT. Most importantly, the results showed that the participants transferred L1 expressions (e.g. endearments) and strategies (e.g. offering the complimented object to the complimenter) to respond to compliments in English. This transfer was influenced by cultural and religious aspects of Kuwaiti society. For instance, Kuwaiti EFL learners were found to use the Return strategy more frequently than British English speakers, since the former tend to attribute complimented behaviour in order to conform to their Islamic teachings. All in all, it has been observed that Kuwaiti EFL learners may not be aware of any culture-specific nature of verbal communications crosslinguistically. Therefore, it is recommended that ESL/EFL teachers need to pay more attention to communicative competence in the target language by organising role play activities in the classroom, for instance. This means that they need not only focus on linguistic competence, but also on sociolinguistic rules of how a language is used in particular social situations. This may enhance students' pragmatic competence and boost their selfconfidence. Finally, studies on the effect of social factors such as distance or age on compliment response strategies by Arab EFL learners could be worthy of further investigation.

\section{Acknowledgment}

Many thanks to Bashayer Alotaibi for her help with the data collection from British English speakers.

\section{References:}

Altakhaineh, A. R. M., \& Rahrouh, H. N. (2015). "The Use of Euphemistic Expressions by Arab EFL Learners: Evidence from Al Ain University of Science and Technology". International Journal of English Linguistics, 5(1), 14-21.

Altakhaineh, A. R. M., \& Zibin, A. (2014). "Perception of Culturally Loaded Words by Arab EFL Learners". International Journal of Linguistics, 6 (3), 122. 
Bialystok, E. (1993). "Symbolic Representation and Attentional Control in Pragmatic Competence". In Kasper, G., \& Blum-Kulka, S. (eds.) Interlanguage Pragmatics (pp. 43-57). Oxford: Oxford University Press.

Blum -Kulka, S. (1982). "Learning to Say What You Mean in a Second Language: A Study of the Speech Act Performance of Learners of Hebrew as a Second Language". Applied Linguistics, 3(3), 29-59.

Blum-Kulka, S., House, J., \& Kasper, G. (1989). "Investigating Crosscultural Pragmatics: An introductory overview". In Blum-Kulka, House \& Kasper (eds). Cross-Cultural Pragmatics: Requests and Apologies (pp. 134). New Jersey: Ablex Publishing Corporation.

Canale, M. (1983). "From Communicative Competence to Communicative Language Pedagogy". In Richards, J. \& Schmidt, R. (ed.) Language and Communication (pp.2-27). London: Longman Group Ltd.

Chang, Y. (1988). Compliments in Chinese Contexts. Unpublished manuscript, University of Illinois at Urbana-Champaign.

Chiang, B., \& Pochtrager, F. (1993). "A Pilot Study of Compliment Responses of American-Born English Speakers and Chinese-Born English Speakers".

Chomsky, N. (1980). Rules and Representations. New York: Columbia University Press.

El Samaty, M. (2005). "Helping Foreign Language Learners Become Pragmatically Competent". Proceedings of the 10th TESOL Arabia Conference, 9, 341-351.

Eslami-Rasekh, Z., Eslami-Rasekh, A., \& Fatahi, A. (2004). "The effect of explicit metapragmatic instruction on the speech act awareness of advanced EFL students". TESL-EJ, 8, 1-12.

Guodong, L., \& Jing, H. (2005). "A Contrastive Study on Disagreement Strategies for Politeness between American English \& Mandarin Chinese". Asian EFL Journal, 7(1), 1-12.

Hatch, E. (1992). Discourse and Language Education. Cambridge: Cambridge University Press.

Herbert, K. (1986). "Say "thank you” or something". American Speech, 61 (1), 76-88.

Holmes, J. (1988). "Paying Compliments: A Sex-Preferential Politeness Strategy". Journal of Pragmatics, 12(4), 445-465.

Holmes, J. (1998). "Complimenting-a Positive Politeness Strategy". Language and gender: A reader, 100-120.

Huth T. (2006). "Negotiating Structure and Culture: L2 Learners' Realization of L2 Compliment-Response Sequences in Talk-in-Interaction". Journal of Pragmatics, 38(12), 2025-2050.

Leech, G .N. (1983). Principles of Pragmatics. London: Longman. 
Liu, D., \& Zhong, S. (1999). "Acquisition of Culturally Loaded Words in EFL". Foreign Language Annals, 32, 177-187. http://dx.doi.org/ 10.1111/j.1944-9720.1999.tb02390.x.

Manes J., \& Wolfson N. (1981). "The Compliment Formula". In F. Coumas (ed.) Conversational Routine: Explorations in Standardized Communication Situations and Prepatterned Speech (pp. 115-132). The Hague: Mouton.

Morris, C. (1938). "Foundations of the Theory of Signs". In Neuratin, O., Carnap, R., \& Morris, C. (eds.) International Encyclopedia of Unified Science. Chicago: University of Chicago Press.

Pomerantz A. (1978). "Compliment Responses: Notes on the Co-operation of Multiple Constraints". In J. Schenkein (ed.) Studies in the Organization of Conversational Interaction (pp. 79-112). New York: Academic Press.

Rizk, S. (2003). "Why Say “NO!” When you Refuse?" TESOL Arabia 2002 Conference Proceedings, 7, 401-431.

Rose, K. (1999). "Teachers and Students Learning about Requests in Hong Kong". In Hinkel, E. (ed.) Culture in Second Language Teaching and Learning. (pp.167-180). Cambridge: Cambridge University Press.

Schmidt, R. (1993). "Consciousness, Learning and Interlanguage Pragmatics". In G. Kasper \& S. Blum-Kulka (eds.) Interlanguage Pragmatics (pp. 21-42). New York: Oxford University Press.

Sternberg, R. J. (1995). In Search of the Human Mind. Fort Worth: Harcourt Brace College Publishers.

Tannen, D. (1993). "The Relativity of Linguistic Strategies: Rethinking Power and Solidarity in Gender and Dominance". In D. Tarnien (ed.) Gender and Conversational Interaction (pp. 156-188). New York: Oxford University Press.

Thomas, J. (1983). "Cross-Cultural Pragmatic Failure". Applied Linguistics, 4, 91-112.

Yoko, U. (2003). "Japanese Compliment Responses: A Comparison to American English norms." Japan Journal of Multilingualism and Multiculturalism, 2, 116-128.

Yoon, K. K. (1991). "Bilingual Pragmatic Transfer in Speech Acts: Bidirectional Responses to a Compliment". In L. Bouton \& Y. Kachru (eds.) Pragmatics and Language Learning. Monograph Series, 2 (pp. 75-100). Urbana-Champaign: University of Illinois. 


\section{Appendix 1}

\section{Discourse Completion Task (DCT)}

Please write what you would say in response to the following compliments. There is no right or wrong answer, so please provide the response exactly as would say it to the person with whom you are communicating:

1. You have just finished presenting your research project in class, on your way back to your seat, one of your classmates says to you: "you were great, well done!". What would you say to her?

2. You invited your female friends over to dinner. After they finish, one of them says to you: "the food was wonderful!". What would you say to her?

3. One of your close female friends sees you at the mall and compliments you on your new dress; she says: "wow, you have a great taste!". What would you say to her?

4. A girl (a complete stranger) sees you in the street and comes up to you and says: "I like your glasses". What would you say to her?

5. You invite your colleagues to have lunch at your house for the first time, when they arrive, one of them says to you: "your house is very nice!". What would you say to her?

6. A girl you meet for the first time in class says to you: " your eyes are really beautiful!". What would you say to her?

7. Your teacher tells you that your performance is improving and that she is very satisfied with your work. What would you say to her?

8. Your boss tells you that she is giving you a promotion for all the hard work you have done. What would you say to her?

9. Your father compliments you on your high grades at school, saying: "I'm proud of you, you are the role model to your siblings". What would you say to him? 


\section{Appendix 2}

\section{Arabic sounds}

\begin{tabular}{|c|c|c|}
\hline Arabic consonants/vowels & Symbols & Description \\
\hline 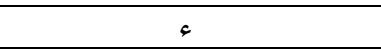 & $?$ & voiceless glottal stop \\
\hline ب & $\mathrm{b}$ & voiced bilabial stop \\
\hline$ت$ & $\mathrm{t}$ & voiceless dento-alveolar stop \\
\hline$\dot{H}$ & $\theta$ & voiceless inter-dental fricative \\
\hline ج & j & voiced post-alveolar affricate \\
\hline$\tau$ & $\underline{\mathrm{h}}$ & voiceless pharyngeal fricative \\
\hline$\dot{\tau}$ & $\mathrm{x}$ & voiceless uvular fricative \\
\hline$د$ & $\mathrm{~d}$ & voiced dento-alveolar stop \\
\hline$\dot{j}$ & $\partial$ & voiced alveolar fricative \\
\hline J & $\mathrm{r}$ & voiced alveo-palatal trill \\
\hline j & $\mathrm{Z}$ & voiced alveolar fricative \\
\hline 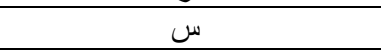 & $\mathrm{s}$ & voiceless alveolar fricative \\
\hline ش & $\int$ & voiceless alveo-palatal fricative \\
\hline ص & $\underline{\mathrm{s}}$ & voiceless alveolar emphatic fricative \\
\hline 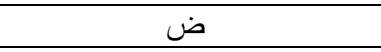 & $\underline{\mathrm{d}}$ & voiced alveolar emphatic stop \\
\hline b & $\underline{\underline{t}}$ & $\begin{array}{c}\text { voiceless dento-alveolar emphatic } \\
\text { stop }\end{array}$ \\
\hline ظ & $\underline{\partial}$ & voiced alveolar emphatic fricative \\
\hline$\varepsilon$ & $\bar{\zeta}$ & voiced pharyngeal fricative \\
\hline$\dot{\varepsilon}$ & $\gamma$ & voiced uvular fricative \\
\hline ف & $\mathrm{f}$ & voiceless labio-dental fricative \\
\hline ق & $q / g^{i}$ & voiceless/voiced uvular stop \\
\hline 5 & $\mathrm{k}$ & voiceless velar stop \\
\hline J & 1 & voiced alveolar lateral \\
\hline 5 & $\mathrm{~m}$ & voiced bilabial nasal \\
\hline ن & $\mathrm{n}$ & voiced alveolar nasal \\
\hline$\circ$ & $\mathrm{h}$ & voiceless glottal fricative \\
\hline 9 & $\mathrm{~W}$ & voiced labio-velar glide \\
\hline ي & $\mathrm{y}$ & voiced palatal glide \\
\hline$\Gamma$ & $\mathrm{a}$ & low short central unrounded \\
\hline 11 & $\mathrm{u}$ & high short back rounded \\
\hline 1.1 & $\mathrm{i}$ & high short front unrounded \\
\hline i & aa & low long central unrounded \\
\hline وو & uu & high long back rounded \\
\hline يبي & ii & high long front unrounded \\
\hline 9 & $0:$ & mid long back rounded \\
\hline او & aw & $\begin{array}{l}\text { low short front unrounded + labio- } \\
\text { velar glide }\end{array}$ \\
\hline اي & ay & $\begin{array}{l}\text { low short front unrounded + palatal } \\
\text { glide }\end{array}$ \\
\hline يبي & ee & mid long front unrounded \\
\hline
\end{tabular}

${ }^{\mathrm{i}}$ These symbols represent the voiceless and voiced uvular stop. 